BNL-112634-2016-JA

\title{
Systematic Theoretical Study of Ethylene Adsorption on delta-MoC(001), TiC(001), and ZrC(001) Surfaces
}

Carlos Jimenez-Orozco, Elizabeth Florez, Andres Moreno, Ping Liu and Jose A. Rodriguez

Submitted to Journal of Physical Chemistry C

June 2016

Chemistry Department

Brookhaven National Laboratory

\author{
U.S. Department of Energy \\ USDOE Office of Science (SC), \\ Basic Energy Sciences (BES) (SC-22)
}

Notice: This manuscript has been authored by employees of Brookhaven Science Associates, LLC under Contract No. DE- SC0012704 with the U.S. Department of Energy. The publisher by accepting the manuscript for publication acknowledges that the United States Government retains a non-exclusive, paid-up, irrevocable, world-wide license to publish or reproduce the published form of this manuscript, or allow others to do so, for United States Government purposes. 


\section{DISCLAIMER}

This report was prepared as an account of work sponsored by an agency of the United States Government. Neither the United States Government nor any agency thereof, nor any of their employees, nor any of their contractors, subcontractors, or their employees, makes any warranty, express or implied, or assumes any legal liability or responsibility for the accuracy, completeness, or any third party's use or the results of such use of any information, apparatus, product, or process disclosed, or represents that its use would not infringe privately owned rights. Reference herein to any specific commercial product, process, or service by trade name, trademark, manufacturer, or otherwise, does not necessarily constitute or imply its endorsement, recommendation, or favoring by the United States Government or any agency thereof or its contractors or subcontractors. The views and opinions of authors expressed herein do not necessarily state or reflect those of the United States Government or any agency thereof. 


\title{
A Systematic Theoretical Study of Ethylene Adsorption on $\delta$-MoC(001),
}

\section{$\mathrm{TiC}(001)$ and $\mathrm{ZrC}(001)$ Surfaces}

Carlos Jimenez-Orozco, ${ }^{\mathrm{a}}$ Elizabeth Florez, ${ }^{\mathrm{b}}$ Andres Moreno, ${ }^{\mathrm{a}}$ Ping Liu ${ }^{\mathrm{c}}$ and Jose A. Rodriguez*${ }^{\mathrm{c}}$

a Química de Recursos Energéticos y Medio Ambiente, Instituto de Química, Facultad de Ciencias Exactas y Naturales, Universidad de Antioquia UdeA; Calle 70 No. 52-21, Medellín, Colombia.

b Departamento de Ciencias Básicas, Universidad de Medellín, Carrera 87 No 30-65, Medellín, Colombia

${ }^{\mathrm{c}}$ Chemistry Department, Brookhaven National Laboratory, Upton, New York 11973, USA.

\begin{abstract}
A systematic study of ethylene adsorption over $\delta$-MoC(001), $\operatorname{TiC}(001)$ and $\mathrm{ZrC}(001)$ surfaces was conducted by means of calculations based on periodic density functional theory. The structure and electronic properties of each carbide surface had a strong influence in the bonding of ethylene. It was found that the metal and carbon sites of the carbide could participate in the adsorption process. As a consequence of this, very different bonding mechanisms were seen on $\delta$-MoC(001) and TiC(001) The bonding of the molecule on the TMC(001) systems showed only minor similarities to the type of bonding found on a typical metal like $\operatorname{Pt}(111)$. In general, the ethylene binding energy on the carbide surfaces was smaller than on the clean metal, with the following trend in stability: $\mathrm{ZrC}(001)<\operatorname{TiC}(001)<\delta-\operatorname{MoC}(001)<\operatorname{Pt}(111)$. The elongation of the $\mathrm{C}=\mathrm{C}$ bond induced by ethylene adsorption on $\delta-\mathrm{MoC}(001)$ and $\mathrm{ZrC}(001)$ was minimal (0.01$0.03 \AA)$. In contrast, the molecule was adsorbed on $\mathrm{TiC}(001)$ in a di- $\sigma-\mathrm{CC}$ mode for which there was a change from $\mathrm{sp}^{2}$ to $\mathrm{sp}^{3}$ hybridization with a large elongation $(0.31 \AA)$ of the $\mathrm{C}=\mathrm{C}$ bond. On the basis of this theoretical study, $\delta$-MoC(001) is proposed as a potential catalyst for the hydrogenation of olefins whereas $\mathrm{TiC}(001)$ could be useful for their hydrogenolysis.
\end{abstract}




\section{Introduction}

Ethylene $\left(\mathrm{C}_{2} \mathrm{H}_{4}\right)$ is a basic building block for the chemical industry and is the largest volume organic chemical produced worldwide. It is commonly used as a benchmark compound in studies of olefin chemistry. The hydrogenation (HYD) reactions of ethylene and other olefins are of primary importance for the production of chemical feedstocks and goods of high commercial value such as solvents, adhesives, nylon derivatives, belts, plasticizers, fibers, resins, food wrap, among others.

Due to its good performance in terms of activity, selectivity and stability, the most studied catalysts for olefin hydrogenation reactions are based on transition metals. The metals generally used for HYD reactions are those of the Pt-group, in addition to Co, Mo, and W. From them, the elements which give better results are those of the Pt-group, due to their superior HYD activity, selectivity and stability. ${ }^{1}$ However, there are two drawbacks concerning the use of Pt-group metals. First, there is a growing demand of clean fuels and products from the petrochemical industry, which implies the use of large amounts of Pt-group metals. This is non-sustainable in the long term, because the relative abundance of these noble metals in the Earth crust is very low. ${ }^{2}$ And second, some hydrocarbon fractions in petroleum refining contain sulfur compounds, which are a poison to Pt-group metal based catalysts deactivating them. ${ }^{3}$

For these reasons, it is important to search materials alternative to Pt-group metals but with similar catalytic performance. Levy \& Boudart ${ }^{4}$ reported a landmark work, where it was shown that tungsten carbide (WC) has a Pt-like catalytic behavior for several HYD reactions. The use of transition metal carbides (TMCs) in HYD reactions has mainly two advantages respect to Ptgroup metals: 1) TMCs are composed with elements more abundant in the Earth crust, leading to a lower cost in commercial markets; and 2) TMCs are much more sulfur resistant than regular 
metals. ${ }^{3}$ The TMCs proposed as alternative catalysts to Pt-group metals are composed with metals of the groups 4-6 of the Periodic Table (known as early TMCs). ${ }^{5}$ The performance of early TMCs as catalyst has been reported for several HYD reactions, including the transformation of $\mathrm{CO}_{2}$ into methane or methanol, ${ }^{6,7}$ the hydrodesulfurization of sulfur compounds like thiophene, ${ }^{8}$ and the hydrogenation of aromatic compounds such as benzene, ${ }^{9}$ toluene, ${ }^{10}$ cumene ${ }^{3}$ and naphthalene. ${ }^{11}$ Also in the production of hydrogen through the water gas shift reaction, electrocatalysis or alkane steam reforming, the TMCs have shown good catalytic potential. ${ }^{12-14}$ Furthermore, the use of TMCs have been reported for ethane hydrogenolysis to form methane, ${ }^{15}$ ethylene decomposition into $\mathrm{C}$ and $\mathrm{H}_{2}{ }^{16}$ and ethylene hydrogenation. ${ }^{17,18}$

To optimize the activity of TMCs in the HYD of olefins, one needs a better understanding of how the carbides bind ethylene and similar compounds at a molecular level. Ethylene is the smallest unsaturated hydrocarbon and can be useful as a probe molecule to study the activity of TMCs in HYD reactions. The purpose of this work is to analyze systematically the interaction of ethylene over $\delta$-MoC(001), $\mathrm{TiC}(001)$ and $\mathrm{ZrC}(001)$ surfaces to evaluate their activity and establish their catalytic potential for the HYD of unsaturated hydrocarbons. This work focuses in an extensive evaluation of several sites for ethylene adsorption using periodic density functional theory as a useful tool to scrutinize the behavior of each TMC surface. To the best of our knowledge, no previous theoretical work has addressed the bonding of ethylene on TMCs substrates. An important issue is the role played by metal and carbon sites of a carbide surface in the bonding of olefin. The presence of surface carbon sites opens the possibility for modes of adsorption not seen on metal surfaces. 


\section{Methodology and computational details}

Calculations based on periodic density functional theory (DFT) were carried out using the CAmbridge Serial Total Energy Package (CASTEP), version 5.5. ${ }^{19}$ Exchange - correlation effects have been accounted by means of the Generalized Gradient Approximation (GGA) using PBE (Purdew - Burke - Ernzerhof) functional ${ }^{20}$ as implemented in CASTEP. Ultra-soft pseudopotentials were used to describe the ionic cores. ${ }^{21}$ The PBE pseudopotentials in CASTEP involves valence electrons $2 s^{2} 2 p^{2}, 4 d^{5} s^{1}, 3 s^{2} 3 p^{6} 3 d^{2} 4 s^{2}$ and $4 s^{2} 4 p^{6} 4 d^{2} 5 s^{2}$ for C, Mo, Ti and $\mathrm{Zr}$ atoms, respectively. The valence electrons were expanded in a plane-wave basis set whose associated kinetic energy do not exceed $350 \mathrm{eV}$ cutoff energy.

A grid of special k-points was used for the numerical integration in the Brillouin zone which were automatically selected by means of the Monkhorst - Pack scheme. ${ }^{22}$ The electronic relaxation was considered converged when total energy in subsequent iterations varied by less than $2 \times 10^{-5} \mathrm{eV}$ and the interatomic forces were lower than $0.05 \mathrm{eV} / \AA$.

Bulk structures were optimized using $5 \times 5 \times 5$ k-points mesh, obtaining the respective cell parameters, which had an error $<3 \%$ respect to the experimental values. Then, from the optimized bulk structure, surface (001) was created by means of the slab surface model, including a vacuum of more than $10 \AA$ between the interlayered slabs arising from periodic symmetry along the direction perpendicular to the surface. The supercell considered was $(2 \times 2)$, with dimensions $\mathrm{a}=\mathrm{b}=8.721 \AA, \mathrm{c}=24 \AA$ for $\delta-\operatorname{MoC}(001), \mathrm{a}=\mathrm{b}=8.659 \AA, \mathrm{c}=24 \AA$ for $\mathrm{TiC}(001)$ and $\mathrm{a}=\mathrm{b}=9.415 \AA, \mathrm{c}=24 \AA$ for $\operatorname{ZrC}(001)$. The optimized bond lengths for the isolated ethylene molecule $(\mathrm{C}-\mathrm{C}=1.33 \AA$ and $\mathrm{C}-\mathrm{H}=1.09 \AA)$ are very close to those observed in experimental studies. ${ }^{23,24}$ 
Four layer slabs were used with the two outermost layers relaxed and the inner layers were kept fixed to represent the bulk. ${ }^{25-29}$ The grid of special k-points used for the numerical integration in the Brillouin zone were automatically selected by means of the Monkhorst - Pack scheme. Enough k-points $(3 \times 3 \times 1)$ were chosen to make sure that there was no significant change in the calculated energies when a larger number of k-points was used.

In several of the calculations, a van der Waals (vdW) correction to the electronic energy was used for the adsorption on TMCs surfaces. This kind of vdW correction has been reported useful to describe dispersive forces in methane ${ }^{30}$ and $\mathrm{CO}_{2}{ }^{6}$ adsorption over a $\delta$-MoC $(001)$ surface. For ethylene adsorption over $\delta$ - $\mathrm{MoC}(001)$ and $\mathrm{ZrC}(001)$ surfaces the dispersion correction implemented within Grimme ${ }^{31}$ was used because for Tkatchenko-Scheffler (TS). ${ }^{32}$ Mo and Zr are not parametrized in CASTEP. For the TiC(001) surface both Grimme and TS were used.

The adsorption energy $\left(E_{\text {ads }}\right)$ was calculated:

$$
E_{\text {ads }}=E\left(T M C_{(001)} a d\right)-\left(E T M C_{(001)}+E_{\text {ethylene }}\right)
$$

In equation (1), $\mathrm{E}\left(\mathrm{TMC}_{(001)} \mathrm{ad}\right)$ is the total energy for the slab with ethylene adsorbed, ETMC $(001)$ is the energy of clean optimized surface slab model and $E_{\text {ethylene }}$ is the energy of ethylene molecule.

\section{Results and discussion}

\subsection{Stable structures of ethylene adsorption on TMC(001) surfaces}


As a point for comparison, we will start examining the interaction of $\operatorname{Pt}(111)$ with ethylene. The molecule was adsorbed on Pt(111) in di- $\sigma-\mathrm{MM}$ and $\pi$-M modes (Figure 1) with binding energies of -1.08 and $-0.78 \mathrm{eV}$, respectively. In the most stable adsorption configuration, di- $\sigma-\mathrm{MM}$ mode, the $\mathrm{C}-\mathrm{C}$ bond distance in ethylene increased from $1.33 \AA$ in gas phase to $1.48 \AA$ on the $\operatorname{Pt}(111)$ surface. Thus, for ethylene on $\operatorname{Pt}(111)$, one observes a relatively large ethylene adsorption energy with a significant distortion (as a consequence of s-p rehybridization) of the adsorbed molecule. These trends are in general agreement with the results of previous theoretical calculations for $\mathrm{C}_{2} \mathrm{H}_{4} / \mathrm{Pt}(111) .{ }^{33-37}$

In principle, the ethylene molecule can adsorb on several sites on the TMC $(001)$ surface. Sites for the $\mathrm{TMC}(001)$ surface are displayed in Figure 2. In the present calculations, for each TMC(001) surface, 19 ethylene geometries were evaluated, which can be divided into two main groups. One of the groups corresponds to the adsorption at the metal sites, either via $\mathrm{C}$ with the molecular plane are parallel to the surface (Notation: H-parallel), or via two $\mathrm{H}$ atoms with its molecular plane perpendicular to the surface (H-down1: C-C axis parallel to the surface, $\mathrm{H}$ down2: C-C axis perpendicular to the surface). The other resembles the adsorption geometries to the $\pi$ - and di- $\sigma$-bonded modes over $\operatorname{Pt}(111)$. ( $\pi$-M or $\pi$-C, Figure 3$)$. For the di- $\sigma$-bond mode, the ethylene carbons can be directed toward $\mathrm{C}_{\text {surface }}$ and/or $\mathrm{M}$ atoms, then when both $\mathrm{C}$ atoms are directed toward two $M$ atoms: di- $\sigma-C C$, di- $\sigma-C M$ and di- $\sigma-M M$ notations in Figure 3. The notations used in this work for $\pi$ - and di- $\sigma$-bonding are consistent with the nomenclature reported in the literature for ethylene adsorption on noble metals. ${ }^{33,34,38,39}$

Before comparing the bonding interactions of ethylene on the carbides, it is necessary to understand structural and electronic differences between the pristine $\operatorname{Pt}(111)$ and the $\delta$ $\mathrm{MoC}(001), \mathrm{TiC}(001)$ and $\mathrm{ZrC}(001)$ surfaces. The bonding of carbon atoms to $\mathrm{Mo}, \mathrm{Ti}$ and $\mathrm{Zr}$ in 
the carbides induces a charge transfer, shown in Figure 4, which obeys the electronegativity difference between $\mathrm{C}$ (2.55), Mo (2.16), $\mathrm{Ti}(1.54)$ and $\mathrm{Zr}$ (1.33) and follows the trend: $\delta$ $\operatorname{MoC}(001)<\operatorname{TiC}(001)<\operatorname{ZrC}(001)$ (see $\mathrm{Q}_{\mathrm{M}}$ in Figure 4). The corresponding geometry parameters are shown in Table 1. The distance between surface metal atoms (M-M) in $\operatorname{Pt}(111)$ is the lowest as shown in Table 1 and the ethylene C-C bond length was $1.33 \AA$. Therefore, the $\mathrm{C}_{2} \mathrm{H}_{4}$ interaction could be favored in a di- $\sigma-\mathrm{MM}$ mode on $\operatorname{Pt}(111)$, however this kind of adsorption could not let to a stable structure on a $\mathrm{TMC}(001)$ surface.

On the $\mathrm{ZrC}(001)$ surface, the distances between surface atoms are larger when compared to $\delta$ $\operatorname{MoC}(001)$ and $\mathrm{TiC}(001)$. As a consequence, the ethylene adsorption on $\operatorname{ZrC}(001)$ could only be favored when $\mathrm{C}_{2} \mathrm{H}_{4}$ interacts with only one surface atom. In contrast, the distances between surface atoms in $\delta-\mathrm{MoC}(001)$ and $\mathrm{TiC}(001)$ were lower than in $\mathrm{ZrC}(001)$, and it is possible that $\mathrm{C}_{2} \mathrm{H}_{4}$ interaction can be done with one or two surface atoms.

The calculated binding energies for all these adsorption modes are shown in the Supporting Information. Table 2 compares the most relevant adsorption energies for the bonding of ethylene on $\operatorname{Pt}(111), \delta-\operatorname{MoC}(001), \operatorname{TiC}(001)$ and $\mathrm{ZrC}(001)$ surfaces. In general, we found that the adsorption energies for ethylene on the $\mathrm{TMC}(001)$ surfaces were in the range of 0.50 to $-0.53 \mathrm{eV}$ without including vdW corrections (see Supporting Information). Thus, we can conclude that ethylene exhibits weaker interactions on the $\mathrm{TMC}(001)$ surfaces than on $\operatorname{Pt}(111)$. The inclusion of a vdW correction enhanced the adsorption energy of ethylene on the TMC $(001)$ surfaces, see Supporting Information. The geometries obtained indicate that the $\mathrm{vdW}$ contribution drives ethylene closer to the surfaces.

The bonding interactions of $\mathrm{C}_{2} \mathrm{H}_{4}$ on the carbides increase following the sequence: $\mathrm{ZrC}(001)<$ $\operatorname{TiC}(001)<\delta-\operatorname{MoC}(001)$. This sequence did not change when vdW corrections were included 
(see Supporting Information). Figure 5 shows the corresponding adsorption geometries for the most stable bonding configurations. As mentioned above, ethylene prefers to bind on $\operatorname{Pt}(111)$ in a di- $\sigma-M M$ mode. In the case of $\delta$-MoC(001), bonding of ethylene in a $\pi$-M configuration (Mo atop site) and via two of its $\mathrm{H}$ atoms exhibit similar stabilities. Over $\mathrm{TiC}(001)$, the molecule clearly prefers a di- $\sigma-\mathrm{CC}$ mode. Finally, on $\mathrm{ZrC}(001)$, the adsorbate is most stable in a $\pi$-M configuration. Adsorption of ethylene on $\delta$-MoC(001) and $\mathrm{ZrC}(001)$ carbide surfaces leads to a minor elongation (0.01-0.03 $\AA$ ) of the $\mathrm{C}$-C bond with respect to the calculated value in gas phase (1.33 A). For the most stable adsorption configurations (Figure 5), only the adsorption on TiC(001) produced a large elongation $(0.31 \AA)$ of the C-C bond. This will be discussed below, in section 3.3. The stability and the $\mathrm{C}-\mathrm{C}$ bond elongation are important for possible reactions of hydrogenation and its causes will be discussed below when we analyze the bonding of ethylene to the carbide surfaces.

Most of the adsorption mode of $\mathrm{C}_{2} \mathrm{H}_{4}$ on $\mathrm{TMC}(001)$ did not modify the surface geometry. The only exception is for the adsorption in a $\pi$-C mode. For this case, the ethylene $\mathrm{C}-\mathrm{C}$ bond was located on top a surface carbon atom, which induced a shift upwards of a carbon atom from the surface, following the trend: $\delta$ - $\operatorname{MoC}(0.65 \AA)>\operatorname{ZrC}(0.47 \AA) \approx \operatorname{TiC}(0.45 \AA)$. It is worth to mention that only on $\delta$-MoC(001) the ethylene adsorption structure in a $\pi$-C mode was stable (see Table 2). The energy required for the surface distortion follows the trend: $\delta$-MoC(001) (1.22 $\mathrm{eV})>\operatorname{TiC}(001)(0.90 \mathrm{eV})=\mathrm{ZrC}(001)(0.90 \mathrm{eV})$. The surface $\delta$-MoC(001) requires more energy to be modified, however, the net adsorption energy on this surface leads to a stable structure weakly bonded (Table 2$)$. On the $\mathrm{TiC}(001)$ and $\mathrm{ZrC}(001)$ surfaces, the energy required to deform the surface was lower, but the net adsorption energies obtained suggest that the adsorption of $\mathrm{C}_{2} \mathrm{H}_{4}$ is not favored. This could be related to the extent of the charge polarization in the surface 
carbon atoms (Figure 4), where there is "an excess" of negative charge in $\mathrm{TiC}(001)$ and $\mathrm{ZrC}(001)$ but the "right" charge in $\delta-\mathrm{MoC}(001)$.

\subsection{Ethylene adsorption on in $\pi-M$ and di- $\sigma-M M$ modes}

\subsubsection{Bonding in $\pi$-M mode on $\delta$-MoC(001) and $\mathrm{ZrC}(001)$}

The $\pi$-M adsorption mode is the most stable structure for ethylene on $\delta$-MoC $(001)$ and $\operatorname{ZrC}(001)$ and the second most stable one in $\operatorname{Pt}(111)$, Table 2. The $\pi$-M adsorptions on $\mathrm{TMC}(001)$ have a similar geometry to that seen on $\operatorname{Pt}(111)$, see Figures 2 and 5. The Mulliken charge for ethylene adsorbed via $\pi$-M mode on $\operatorname{Pt}(111), \delta$-MoC(001) and $\mathrm{ZrC}(001)$ surfaces were $-0.40 \mathrm{e},-0.45 \mathrm{e}$ and $-0.39 \mathrm{e}$, respectively. This suggests that ethylene bonding to the TMC $(001)$ surfaces has a minor ionic contribution in the adsorption via $\pi-\mathrm{M}$ mode, which is observed in the charge density difference (CDD) analysis (see Figure 6), where the ionic contribution decreases from $\delta$ $\mathrm{MoC}(001)$ to $\mathrm{ZrC}(001)$ (blue regions in between ethylene and surface). The ionic contribution to the bonding is related to the extent of the binding energy of $\mathrm{C}_{2} \mathrm{H}_{4}$, following the trend:

$$
\operatorname{ZrC}(001)\left(\mathrm{E}_{\mathrm{ads}}=-0.12 \mathrm{eV}\right)<\delta-\mathrm{MoC}(001)\left(\mathrm{E}_{\mathrm{ads}}=-0.53 \mathrm{eV}\right)
$$

The $\mathrm{CDD}$ for $\delta-\operatorname{MoC}(001)$ has more similarities to that of $\operatorname{Pt}(111)$ than to the one of $\operatorname{ZrC}(001)$. Therefore, among the $\mathrm{TMC}(001)$ studied, the $\delta$-MoC(001) has the most $\mathrm{Pt}(111)$-like behavior in the adsorption of ethylene via a $\pi$-M mode.

In gas phase, $\mathrm{C}-\mathrm{C}$ and $\mathrm{C}-\mathrm{H}$ bond lengths of ethylene were $1.33 \AA$ and $1.09 \AA$, respectively. After adsorption on $\mathrm{Pt}(111)$ the $\mathrm{C}-\mathrm{C}$ increased to $1.41 \AA$ (Figure 1b), which indicated that ethylene was activated on $\mathrm{Pt}(111)$ surface as expected, due to a change in $\mathrm{C} \mathrm{sp}^{2}$ hybridization geometry. For 
ethylene on $\delta-\mathrm{MoC}(001)$, there was not significant modification of ethylene structures, indicating that this structure was not activated when bonding to the surface.

The bonding of olefins to metals is usually described by means of the Dewar-Chatt-Duncanson (D-C-D) mechanism, based on a molecular orbital bond description. ${ }^{40,41}$ This model suggests that bonding between an olefin and a metal forms a triangle C-M-C similar to the structures shown in Figure $3 \mathrm{a}$. For the bonding, there is an electron transfer from the ethylene $\pi$-orbital (HOMO) to the metal, together with a back-donation from d-orbitals of the metal to an empty ethylene $\pi^{*}$-antibonding orbital (LUMO). Hence, the ethylene C-C bond is weakened, together with the elongated C-C bond length (Figure 1). This effect is clearly seen on $\operatorname{Pt}(111)$, however, the adsorption on $\mathrm{TMC}(001)$ in $\pi$-M mode is rather weak and does not change the geometry parameters of the ethylene in gas phase (i.e. ethylene is not activated). Different from metal surfaces, every $\mathrm{M}$ atom on the $\mathrm{TMC}(001)$ surfaces is surrounded by four $\mathrm{C}$ atoms and $\mathrm{M}$ is oxidized into $\mathrm{M}^{\delta+}$ due to a net charge transfer from $\mathrm{M}$ to $\mathrm{C} . \mathrm{M}^{\delta+}$ is not capable as $\mathrm{M}$ for backdonation into the ethylene $\pi^{*}$-antibonding orbital and, therefore, the molecule cannot be activated.

\subsubsection{Lack of stability of di- $\sigma$-MM mode on the carbide surfaces}

The adsorption of ethylene in the di- $\sigma-\mathrm{MM}$ mode produced the most stable structure on $\mathrm{Pt}(111)$, substantially activating the adsorbate (see Table 2), where the C-C bond length increased from $1.33 \AA$ to $1.48 \AA$ (see Table 1 and Figure 1a) and there was a change in hybridization from sp ${ }^{2}$ to $\mathrm{sp}^{3}$-like. However, the structures obtained for $\mathrm{TMC}(001)$ in the di- $\sigma-\mathrm{MM}$ mode were not stable (Table 2) and, thus, did not induce change in the adsorbate geometry. This is in agreement with 
the M-M distance (Table 1), where the distance between surface metal atoms follow the trend: $\operatorname{Pt}(111)<\operatorname{TiC}(001)<\delta-\operatorname{MoC}(001)<\mathrm{ZrC}(001)$, which obeys the order of adsorption structure stability.

\subsection{Ethylene adsorption in $\pi-\mathrm{C}$, di- $\sigma-\mathrm{CC}$ and $\sigma-\mathrm{C}$ modes}

In Figure 4, the carbon surface sites exhibit a large negative charge. In principle, these centers may not act as simple spectators in the bonding of the ethylene molecule. The presence of these surface carbon atoms opens the possibility of bonding modes not seen on pure metal surfaces.

\subsubsection{Bonding in $\pi-\mathrm{C}$ mode on $\delta$-MoC(001)}

On the carbide surfaces, this kind of adsorption is stable only on the $\delta$-MoC(001) surface, Table 2. Interestingly, the adsorption energy is relatively small $(-0.10 \mathrm{eV})$ but there was a significant elongation of the $\mathrm{C}-\mathrm{C}$ bond of the adsorbate reaching a value of $1.50 \AA$, achieving a $\mathrm{C}-\mathrm{C}$ bond length close to ethane $(1.53 \AA)$ and modifying $\mathrm{sp}^{2}$ hybridization where $\mathrm{H}$ atoms are located in a distribution close to a $\mathrm{sp}^{3}$-like geometry. The extent of the increase in $\mathrm{C}-\mathrm{C}$ bond length via $\pi$-C mode was similar to the $\mathrm{C}-\mathrm{C}$ obtained for $\mathrm{Pt}(111)$ via the di- $\sigma-\mathrm{MM}$ mode. Differently, the C-C bond elongation on $\delta$-MoC(001) was not associated with a strong energy as the case of $\operatorname{Pt}(111)$.

The energy gain due to the strong ethylene-surface interaction was partly released during a companied surface distortion (Figure 7), which was not observed in the adsorption modes evaluated above. The adsorption of $\mathrm{C}_{2} \mathrm{H}_{4}$ induced a shift upwards of a carbon atom from the surface. The distance between ethylene carbons and that modified surface $\mathrm{C}$ atom was $\approx 1.6 \AA$, close to a single $\mathrm{C}-\mathrm{C}$ bond length. The surface distortion after $\mathrm{C}_{2} \mathrm{H}_{4}$ bonding in $\pi$-C mode had an energy cost that was compensated by bonding of the molecule to the $\mathrm{C}$ surface atom, but the 
overall binding energy was very small $(-0.10 \mathrm{eV})$. Thus, a modification of the surface structure is not an advantage in terms of net stability.

\subsubsection{Bonding in di- $\sigma-\mathrm{CC}$ mode on $\mathrm{TiC}(001)$ and $\sigma-\mathrm{C}$ mode on $\delta$-MoC(001)}

The ethylene adsorption in a di- $\sigma-\mathrm{CC}$ was only stable on $\mathrm{TiC}(001)$ surface, with a binding energy of $-0.45 \mathrm{eV}$ (see Table 2). Additionally, this adsorption produces a remarkable increase in C-C bond length from $1.33 \AA$ to $1.64 \AA$, a change of $\mathrm{sp}^{2}$ hybridization geometry (Figure 8a) and a closer approach to a surface carbon atom $(1.58 \AA)$ at a distance close to a single C-C bond. It is worth to mention that adsorption via di- $\sigma-\mathrm{CC}$ and $\sigma-\mathrm{C}$ modes did not induce to surface distortion.

Contrary to the adsorption in $\pi$-M and $\pi$-C modes, in di- $\sigma-\mathrm{CC}$ mode, the bonding of ethylene have mainly a covalent contribution. As shown in the CDD analysis (Figure 8a, red zones in between ethylene and surface), every ethylene carbon forms a covalent bond with a $\mathrm{C}_{\text {surface, }}$, leading to a very stable structure and a modified electronic structure of the ethylene after adsorption. The formation of a covalent $\mathrm{C}_{\text {ethylene }}-\mathrm{C}_{\text {surface }}$ bond involves sharing of electrons between both carbon atoms, weakening the ethylene $\mathrm{C}-\mathrm{C}$ bond with the $\mathrm{C}-\mathrm{C}$ bond length going from 1.33 to $1.64 \AA$, which is a bond length even higher than the single $\mathrm{C}-\mathrm{C}$ bond in ethane (1.53 $\AA)$. This behavior suggests that the $\mathrm{TiC}(001)$ surface could be a good candidate in hydrogenolysis reactions.

For the adsorption on $\operatorname{TMC}(001)$ via $\sigma-\mathrm{C}$ mode, the structure obtained was only stable on $\delta$ $\mathrm{MoC}(001)$, see Table 2. The optimized structure conducted to a rotation of the ethylene C-C bond axis $\approx 45^{\circ}$ respect to the surface plane, favoring interaction to only one surface carbon atom 
and avoiding the Mo atom, forming a covalent bond between both carbon atoms, where the $\mathrm{C}_{\text {ethylene }}-\mathrm{C}_{\text {surface }}$ bond length was around $1.53 \AA$, achieving a single $\mathrm{C}-\mathrm{C}$ bond length.

\subsection{Ethylene adsorption with hydrogen atoms directed toward the carbide surface}

In all the adsorption modes considered until this point, both the ethylene $\mathrm{C}-\mathrm{C}$ and $\mathrm{C}-\mathrm{H}$ bond axes were parallel to the surface. However, after evaluating some modes with $\mathrm{H}$ atoms pointing towards the surface (H-down1 configuration, see Figure 2), some stable adsorption structures were obtained.

This kind of adsorption on $\operatorname{Pt}(111)$ was not stable (Table 2) and the ethylene was not activated.

On the carbide surfaces, it was only stable on $\delta-\mathrm{MoC}(001)$ with an adsorption energy of $-0.53 \mathrm{eV}$ (Figure $8 b$ ), favorable as the structure obtained via the $\pi-\mathrm{M}$ mode, in contrast, on $\mathrm{TiC}(001)$ and $\mathrm{ZrC}(001)$ these adsorption structures were not stable. The stability follows the trend: $\delta$ $\operatorname{MoC}(001)>>\operatorname{TiC}(001)>\operatorname{ZrC}(001)$.

In all the cases considered on the $\delta$-MoC(001) surface, the adsorption through hydrogen atoms let to stable structures, but the ethylene was not activated in any case. The most stable structure was obtained when every $\mathrm{H}$ atom was directed toward one surface carbon atom (see Figure $8 \mathrm{~b}$ ). There was a slight charge transfer towards $\mathrm{H}$ atoms (blue zone in Figure 8b). The H-like-bridge between adsorbate and the surface leads to a stability due to the distribution of charges in $\mathrm{H}$ atoms and $\mathrm{C}_{\text {surface }}$ atoms (blue zones in Figure $8 \mathrm{~b}$ ) trying to form a $\mathrm{C}-\mathrm{H}$ bond, rather than in $\mathrm{C}-\mathrm{C}$ bonds of ethylene. 


\subsection{The use of $\mathrm{TMC}(001)$ surfaces as catalysts in hydrogenation and hydrogenolysis reactions}

The activity of TMCs in hydrogenation and hydrogenolysis reactions is well established but the associated chemistry is not yet fully understood. For an analysis of the catalytic potential of the $\mathrm{TMC}(001)$ surfaces in the hydrogenation of olefins, one first needs to understand the bonding of the reactant adsorbates on these surfaces.

Florez et. al ${ }^{27,42}$ reported a good capability of $\mathrm{ZrC}(001)$ and $\mathrm{TiC}(001)$ to adsorb and dissociate the hydrogen molecule while the interaction on $\delta$-MoC(001) was weak. However, in the study reported by Posada-Perez et al. ${ }^{7}$ (PBE functional), the adsorption of $\mathrm{H}_{2}$ on $\delta$-MoC(001) and $\mathrm{TiC}(001)$ has a similar behavior and $\mathrm{ZrC}(001)$ the best performance. The difference relies on the functional used in both studies. We notice that the trends for $\mathrm{H}_{2}$ adsorption from previous studies ${ }^{7,27}$ and that for $\mathrm{C}_{2} \mathrm{H}_{4}$ (this work) adsorption are different:

$$
\begin{array}{ll}
\mathrm{H}_{2}: & \mathrm{ZrC}(001)>\operatorname{TiC}(001)>\delta-\operatorname{MoC}(001) \\
\mathrm{C}_{2} \mathrm{H}_{4}: & \delta-\operatorname{MoC}(001)>\operatorname{TiC}(001)>\mathrm{ZrC}(001)
\end{array}
$$

On $\mathrm{ZrC}(001)$ and $\delta$-MoC(001) there is an opposite behavior for $\mathrm{H}_{2}$ and $\mathrm{C}_{2} \mathrm{H}_{4}$ binding to the surface but $\mathrm{TiC}(001)$ has an intermediate behavior with both adsorbates. The difference relies on the nature of both the surface and the adsorbate. The interaction of ethylene on $\delta$-MoC(001) and $\mathrm{TiC}(001)$ was favored, in part, due to the geometry parameters of the surface, where the distance between carbon and metal atoms is shorter (compared to $\mathrm{ZrC}(001)$. Therefore, the size of the adsorbate has an important effect in the adsorption on TMC(001) surfaces. Additionally, the 
extent of the charge polarization in $\mathrm{ZrC}(001)$ pristine surface atoms limits $\mathrm{C}_{2} \mathrm{H}_{4}$ adsorption but favors $\mathrm{H}_{2}$ interactions, which is a consequence of the adsorbate nature. The study of the interaction of $\mathrm{C}_{2} \mathrm{H}_{4}$ with $\mathrm{H}_{2}$ on the carbide surfaces is beyond the scope of this study and will be a matter of future work, but from the present work it is clear that there can be substantial differences depending on the intrinsic nature of the carbide surface.

The results obtained in this study suggest that $\delta-\operatorname{MoC}(001)$ has the greatest potential to be used in hydrogenation reactions, due to the stability of ethylene adsorbed structures and the capability to activate the molecule. Another advantage is that ethylene is not occupying the sites for dissociative chemisorption of $\mathrm{H}_{2},{ }^{27}$ as it happens on $\mathrm{TiC}(001)$. It is worth to mention that $\delta$ $\mathrm{MoC}(001)$ is more resistant to be oxidized in comparison with other early $\mathrm{TMC}(001),{ }^{26}$ which is an advantage in terms of avoiding surface deactivation in oxidizing atmospheres.

The $\mathrm{ZrC}(001)$ surface did not present stable structures for ethylene adsorption, therefore this limits its capability as catalyst involving olefins. This drawback could be overcome using $\mathrm{ZrC}(001)$ as support of metals like $\mathrm{Au}$, similarly as reported for $\mathrm{TiC}(001)$, where its performance was improved after depositing Au, showing good results for hydrogen dissociation reactions, ${ }^{42}$ $\mathrm{CO}$ oxidation, $\mathrm{SO}_{2}$ destruction and tiophene hydrodesulfurization. ${ }^{43}$

Ethylene adsorption on $\mathrm{TiC}(001)$ led to an elongation of the C-C bond length (1.64 $\AA$ ) even beyond the bond distance of ethane (1.53 $\AA$ ). The use of $\mathrm{TiC}(001)$ could favor the C-C bond dissociation, which is an advantage in hydrogenolysis reactions, suggesting that not only ethane (used for these kind of reactions ${ }^{44}$ ) but ethylene could be used in hydrogenolysis reactions. This could also serve as a basis to further treat complex molecules and transform them into smaller products of interest in academia and industry, further studies are necessary. 
For hydrogenation reactions, molybdenum carbide has been extensively reported as a potential catalyst. ${ }^{3,10-12,45,46}$ There are several crystal phases of molybdenum carbide, ${ }^{47}$ but the most applied in catalysis are $\alpha-\mathrm{Mo}_{2} \mathrm{C}$ (hexagonal) ${ }^{3,48-50}$ and $\beta-\mathrm{Mo}_{2} \mathrm{C}$ (orthorhombic). ${ }^{6,51,52}$ Something interesting is that the activity, stability and selectivity are function of the crystal structure. ${ }^{50,53}$ For example, for the hydrogenation of $\mathrm{CO}_{2}$ on $\mathrm{MoC}$ and $\mathrm{Mo}_{2} \mathrm{C}$, the catalytic activity and selectivity towards methanol formation depends strongly on the metal/carbon ratio in the carbide. ${ }^{6,53}$ Our work is the first step in an effort for the application of $\delta$-MoC in hydrogenation reactions of olefins. The results obtained indicate that a catalyst with $\mathrm{Mo} / \mathrm{C}=1(\delta-\mathrm{MoC})$ has a good potential, but further studies are required to establish its selectivity and stability. Furthermore, an analysis of ethylene adsorption on $\mathrm{Mo}_{2} \mathrm{C}$ surfaces is necessary to understand its capabilities for olefins hydrogenation and complement the analysis shown in this work for the $\delta$-MoC $(001)$ surface.

\section{Summary and Conclusions}

The adsorption of ethylene was extensively and systematically analyzed over $\delta$-MoC $(001)$, $\mathrm{TiC}(001)$ and $\mathrm{ZrC}(001)$ surfaces by means of calculations based on periodic density functional theory, using the Perdew-Burke-Ernzerhof exchange-correlation functional and explicitly accounting for the dispersive force description as proposed by Grimme and TkatchenkoScheffler.

Three bonding configurations (H-parallel, $\mathrm{H}$-down 1 and $\mathrm{H}$-down2) and nineteen structures were evaluated for every carbide, in total 57 structures were analyzed to cover all possible adsorption 
sites on the $\mathrm{TMC}(001)$ surfaces. Some adsorption modes were evaluated on $\operatorname{Pt}(111)$ as a reference. The adsorption energy was accounted with and without dispersive forces contribution. The effect of $\mathrm{vdW}$ in the geometry was a slight closer approach of ethylene to the surface, but the rest of geometrical parameters remained invariable.

The structure and electronic properties of each carbide surface has a strong influence in the bonding of ethylene on $\delta$ - $\mathrm{MoC}(001), \operatorname{TiC}(001)$ and $\mathrm{ZrC}(001)$ surfaces. Metal and carbon centers can participate in the adsorption process. The bonding of ethylene had both ionic and covalent contributions, depending on the adsorption site and the bonding configuration. The adsorption via a di- $\sigma-\mathrm{MM}$ mode leads to stable structure on $\operatorname{Pt}(111)$, but on the $\mathrm{TMC}(001)$ surfaces this bonding configuration was not stable. The most stable structure in $\delta$-MoC(001) and $\mathrm{ZrC}(001)$ had a similar adsorption geometry to $\mathrm{Pt}(111)$ in a $\pi$-M mode, but the ethylene was not activated on these TMC(001) surfaces. For the di- $\sigma-C C$ adsorption mode, the most stable structure was found on $\mathrm{TiC}(001)$, where the ethylene was also activated. The results obtained indicate that activation of ethylene is only possible when the $\mathrm{H}$ atoms of the molecule are not directed toward the surface.

Of the studied surfaces, $\delta$-MoC(001) has the greatest potential to be used in hydrogenation reactions. $\mathrm{ZrC}(001)$ alone was not active, but its performance could be improved by supporting some metals. On the other hand, $\mathrm{TiC}(001)$ could be another candidate for hydrogenation reactions, but the large increase seen for the $\mathrm{C}-\mathrm{C}$ bond length suggests that this surface may be applied also in hydrogenolysis reactions.

\section{Acknowledgments}


Part of this research was carried out at Brookhaven National Laboratory in the Chemistry Department and the calculations were performed using the computer facility at the Center for Functional Nanomaterials, which is a user facility of U.S. DOE Office of Science, under Contract No. DE-SC0012704. C.J-O acknowledges his PhD scholarship provided by the Colombian National Science Foundation (COLCIENCIAS).

\section{Supporting Information}

Tables showing the binding energies for all the adsorption modes investigated for the adsorption of ethylene on $\delta-\operatorname{MoC}(001), \operatorname{TiC}(001)$ and $\operatorname{ZrC}(001)$ surfaces.

\section{References}

(1) Marcilly, C. Catalyse Acido-Basique. Application Au Raffinage at à La Pétrochimie; Institute Français du Pétrole: Paris, 2003.

(2) Greenwood, N.; Earnshaw, A. Chemistry of the Elements, 2nd ed.; Elsevier ButterworthHeinemann: India, 1997.

(3) Dhandapani, B.; St. Clair, T.; Oyama, S. T. Simultaneous Hydrodesulfurization, Hydrodeoxygenation, and Hydrogenation with Molybdenum Carbide. Appl. Catal. A Gen. 1998, 168 (2), 219-228.

(4) Levy, R. .; Boudart, M. Platinum-Like Behavior of Tungsten Carbide in Surface Catalysis. Science 1973, 181 (4099), 547-549.

(5) Liu, Y.; Kelly, T. G.; Chen, J. G.; Mustain, W. E. Metal Carbides as Alternative Electrocatalyst Supports. ACS Catal. 2013, 3, 1184-1194.

(6) Posada-Pérez, S.; Viñes, F.; Ramirez, P. J.; Vidal, A. B.; Rodriguez, J. A.; Illas, F. The Bending Machine: $\mathrm{CO} 2$ Activation and Hydrogenation on $\delta-\mathrm{MoC}(001)$ and $\beta-\mathrm{Mo} 2 \mathrm{C}(001)$ Surfaces. Phys. Chem. Chem. Phys. 2014, 16 (28), 14912-14921.

(7) Posada-Pérez, S.; Viñes, F.; Rodriguez, J. A.; Illas, F. Fundamentals of Methanol Synthesis on Metal Carbide Based Catalysts: Activation of CO2 and H2. Top. Catal. 2015, 58 (2-3), 159-173.

(8) Rodriguez, J. A.; Liu, P.; Takahashi, Y.; Nakamura, K.; Viñes, F.; Illas, F. Desulfurization of Thiophene on $\mathrm{Au} / \mathrm{TiC}(001)$ : Au-C Interactions and Charge Polarization. J. Am. Chem. Soc. 2009, 131 (001), 8595-8602.

(9) Rocha, A. S.; Rocha, A. B.; da Silva, V. T. Benzene Adsorption on Mo2C: A Theoretical and Experimental Study. Appl. Catal. A Gen. 2010, 379 (1-2), 54-60. 
(10) Frauwallner, M. L.; López-Linares, F.; Lara-Romero, J.; Scott, C. E.; Ali, V.; Hernández, E.; Pereira-Almao, P. Toluene Hydrogenation at Low Temperature Using a Molybdenum Carbide Catalyst. Appl. Catal. A Gen. 2011, 394 (1-2), 62-70.

(11) Ardakani, S. J.; Smith, K. J. A Comparative Study of Ring Opening of Naphthalene, Tetralin and Decalin over Mo2C/HY and Pd/HY Catalysts. Appl. Catal. A Gen. 2011, 403 (1-2), 36-47.

(12) Hwu, H. H.; Chen, J. G. Surface Chemistry of Transition Metal Carbides. Chem. Rev. 2005, 105 (1), 185-212.

(13) Vojvodic, A. Steam Reforming on Transition-Metal Carbides from Density-Functional Theory. Catal. Letters 2012, 142 (6), 728-735.

(14) Rodriguez, J. a.; Ramírez, P. J.; Asara, G. G.; Viñes, F.; Evans, J.; Liu, P.; Ricart, J. M.; Illas, F. Charge Polarization at a Au-TiC Interface and the Generation of Highly Active and Selective Catalysts for the Low-Temperature Water-Gas Shift Reaction. Angew. Chemie Int. Ed. 2014, 53 (42), 11270-11274.

(15) Qi, K.-Z.; Wang, G.-C.; Zheng, W.-J. Structure-Sensitivity of Ethane Hydrogenolysis over Molybdenum Carbides: A Density Functional Theory Study. Appl. Surf. Sci. 2013, 276, 369-376.

(16) Frühberger, B.; Chen, J. G. Reaction of Ethylene with Clean and Carbide-Modified Mo(110): Converting Surface Reactivities of Molybdenum to Pt-Group Metals. J. Am. Chem. Soc. 1996, 118 (110), 11599-11609.

(17) Moreno-Castilla, C.; Alvarez-Merino, M. A.; Carrasco-Marín, F.; Fierro, J. L. G. Tungsten and Tungsten Carbide Supported on Activated Carbon: Surface Structures and Performance for Ethylene Hydrogenation. Langmuir 2001, 17, 1752-1756.

(18) Cui, X.; Zhou, X.; Chen, H.; Hua, Z.; Wu, H.; He, Q.; Zhang, L.; Shi, J. In-Situ Carbonization Synthesis and Ethylene Hydrogenation Activity of Ordered Mesoporous Tungsten Carbide. Int. J. Hydrogen Energy 2011, 36 (17), 10513-10521.

(19) Segall, M. D.; Probert, M. J.; Pickard, C. J.; Hasnip, P. J.; Clark, S. J.; Refson, K.; Payne, M. C. First Principles Methods Using CASTEP. Zeitschrift fuer Krist. 2005, 220 (5-6), 567-570.

(20) Perdew, J. P.; Burke, K.; Ernzerhof, M. Generalized Gradient Approximation Made Simple. Phys. Rev. Lett. 1996, 77 (18), 3865-3868.

(21) Vanderbilt, D. Soft Self-Consistent Pseudopotentails in a Generalized Eigenvalue Formalism. Phys. Rev. B Rapid Commun. 1990, 41 (11), 7892-7895.

(22) Monkhorst, H. J.; Pack, J. D. Special Points for Brillouin-Zone Integrations. Phys. Rev. B 1976, 13 (12), 5188-5192.

(23) Gallaway, W. S.; Barker, E. F. The Infra-Red Absorption Spectra of Ethylene and Tetra-DeuteroEthylene under High Resolution. J. Chem. Phys. 1942, 10 (2), 88-97.

(24) Herzberg, G.; Stoicheff, B. P. Carbon-Carbon and Carbon-Hydrogen Distances in Simple Polyatomic Molecules. Nature 1955, 175, 79-80.

(25) Politi, J. R. D. S.; Viñes, F.; Rodriguez, J. A.; Illas, F. Atomic and Electronic Structure of Molybdenum Carbide Phases: Bulk and Low Miller-Index Surfaces. Phys. Chem. Chem. Phys. 2013, 15 (30), 12617-12625.

(26) Viñes, F.; Sousa, C.; Illas, F. A Systematic Density Functional Study of Molecular Oxygen Adsorption and Dissociation on the ( 001 ) Surface of Group IV - VI Transition Metal Carbides. J. Phys. Chem. C 2007, 111 (001), 16982-16989. 
(27) Florez, E.; Gomez, T.; Rodriguez, J. A.; Illas, F. On the Dissociation of Molecular Hydrogen by Au Supported on Transition Metal Carbides: Choice of the Most Active Support. Phys. Chem. Chem. Phys. 2011, 13 (15), 6865-6871.

(28) Gomez, T.; Florez, E.; Rodriguez, J. A.; Illas, F. Reactivity of Transition Metals (Pd, Pt, Cu, Ag, $\mathrm{Au}$ ) toward Molecular Hydrogen Dissociation: Extended Surfaces versus Particles Supported on TiC(001) or Small Is Not Always Better and Large Is Not Always Bad. J. Phys. Chem. C 2011, 115 (001), 11666-11672.

(29) Viñes, F.; Sousa, C.; Liu, P.; Rodriguez, J. A.; Illas, F. A Systematic Density Functional Theory Study of the Electronic Structure of Bulk and (001) Surface of Transition-Metals Carbides. $J$. Chem. Phys. 2005, 122 (17), 174709.

(30) Posada-Pérez, S.; dos Santos Politi, J. R.; Viñes, F.; Illas, F. Methane Capture at Room Temperature: Adsorption on Cubic $\delta$-MoC and Orthorhombic $\beta$-Mo2C Molybdenum Carbide (001) Surfaces. RSC Adv. 2015, 5 (43), 33737-33746.

(31) Grimme, S. Semiempirical GGA-Type Density Functional Constructed with a Long-Range Dispersion Correction. J. Comput. Chem. 2006, 27 (15), 1787-1799.

(32) Tkatchenko, A.; Scheffler, M. Accurate Molecular Van Der Waals Interactions from Ground-State Electron Density and Free-Atom Reference Data. Phys. Rev. Lett. 2009, 102 (7), 073005.

(33) Becker, C.; Haubrich, J.; Wandelt, K.; Delbecq, F.; Loffreda, D.; Sautet, P. Adsorption of Simple Alkenes on Pt(111) and Pt-Sn Surface Alloys: Bond Strength versus Heat of Adsorption. J. Phys. Chem. C 2008, 112 (111), 14693-14695.

(34) Ditlevsen, P. D.; Hove, M. A. Van; Somorjai, G. A. Molecular Modeling of Ethylene Decomposition on Platinum Surfaces. Surf. Sci. 1993, 292, 267-275.

(35) Watwe, R. Density Functional Theory (DFT) Studies of C1 and C2 Hydrocarbons Species on Pt Clusters. J. Catal. 1998, 180 (2), 184-193.

(36) Basaran, D.; Aleksandrov, H. A.; Chen, Z. X.; Zhao, Z. J.; Rösch, N. Decomposition of Ethylene on Transition Metal Surfaces M(111). A Comparative DFT Study of Model Reactions for $\mathrm{M}=\mathrm{Pd}$, Pt, Rh, Ni. J. Mol. Catal. A Chem. 2011, 344 (1-2), 37-46.

(37) Ge, Q.; King, D. A. The Chemisorption and Dissociation of Ethylene on Pt $\{111\}$ from First Principles. J. Chem. Phys. 1999, 110 (10), 4699.

(38) Sautet, P.; Paul, J. F. Low Temperature Adsorption of Ethylene and Butadiene on Platinum and Palladium Surfaces: A Theoretical Study of the Diø/ $\pi$ Competition. Catal. Letters 1991, 9 (3-4), 245-260.

(39) Spiewak, B. E.; Cortright, R. D.; Dumesic, J. A. Microcalorimetric Studies of H2, C2H4 and C4H2 Adsorption on Pt Powder. J. Catal. 1998, 176, 405-414.

(40) Hartley, B. F. R. Metal-Olefin and -Acetylene Bonding in Complexes. Angew. Chemie - Int. Ed. 1972, 11 (7), 596-606.

(41) Blomberg, M. R. a; Siegbahn, P. E. M.; Svensson, M. Theoretical Study of the Binding of Ethylene to Second-Row Transition-Metal Atoms. J. Phys. Chem. 1992, 96 (49), 9794-9800.

(42) Florez, E.; Gomez, T.; Liu, P.; Rodriguez, J. A.; Illas, F. Hydrogenation Reactions on $\mathrm{Au} / \mathrm{TiC}(001)$ : Effects of Au-C Interactions on the Dissociation of H2. ChemCatChem 2010, 2 (10), 1219-1222.

(43) Rodriguez, J. A.; Liu, P.; Takahashi, Y.; Viñes, F.; Feria, L.; Florez, E.; Nakamura, K.; Illas, F. 
Novel Au-TiC Catalysts for CO Oxidation and Desulfurization Processes. Catal. Today 2011, 166 (1), 2-9.

(44) Salciccioli, M.; Chen, Y.; Vlachos, D. G. Microkinetic Modeling and Reduced Rate Expressions of Ethylene Hydrogenation and Ethane Hydrogenolysis on Platinum. Ind. Eng. Chem. Res. 2011, $50(1), 28-40$.

(45) Furimsky, E. Metal Carbides and Nitrides as Potential Catalysts for Hydroprocessing. Appl. Catal. A Gen. 2003, 240 (1-2), 1-28.

(46) Ardakani, S. J.; Liu, X.; Smith, K. J. Hydrogenation and Ring Opening of Naphthalene on Bulk and Supported Mo2C Catalysts. Appl. Catal. A Gen. 2007, 324, 9-19.

(47) Hugosson, H. W.; Eriksson, O.; Nordström, L.; Jansson, U.; Fast, L.; Delin, A.; Wills, J. M.; Johansson, B. Theory of Phase Stabilities and Bonding Mechanisms in Stoichiometric and Substoichiometric Molybdenum Carbide. J. Appl. Phys. 1999, 86 (7), 3758-3767.

(48) Wang, T.; Li, Y.-W.; Wang, J.; Beller, M.; Jiao, H. Dissociative Hydrogen Adsorption on the Hexagonal Mo2C Phase at High Coverage. J. Phys. Chem. C 2014, 118 (15), 8079-8089.

(49) Luo, Q.; Wang, T.; Walther, G.; Beller, M.; Jiao, H. Molybdenum Carbide Catalysed Hydrogen Production from Formic Acid - A Density Functional Theory Study. J. Power Sources 2014, 246, $548-555$.

(50) Vitale, G.; Guzmán, H.; Frauwallner, M. L.; Scott, C. E.; Pereira-Almao, P. Synthesis of Nanocrystalline Molybdenum Carbide Materials and Their Characterization. Catal. Today 2015, 250, 123-133.

(51) Liu, P.; Rodriguez, J. A. Water-Gas-Shift Reaction on Molybdenum Carbide Surfaces: Essential Role of the Oxycarbide. J. Phys. Chem. B 2006, 110, 19418-19425.

(52) Schweitzer, N. M.; Schaidle, J. a; Ezekoye, O. K.; Pan, X.; Linic, S.; Thompson, L. T. High Activity Carbide Supported Catalysts for Water Gas Shift. J. Am. Chem. Soc. 2011, 133 (8), 23782381.

(53) Xu, W.; Ramirez, P. J.; Stacchiola, D.; Rodriguez, J. A. Synthesis of $\alpha-M o C 1-X$ and $\beta-M o C y$ Catalysts for $\mathrm{CO} 2$ Hydrogenation by Thermal Carburization of Mo-Oxide in Hydrocarbon and Hydrogen Mixtures. Catal. Letters 2014, 144 (8), 1418-1424. 
Table 1. Geometry parameters of Pt, $\delta-\mathrm{MoC}, \mathrm{TiC}$ and $\mathrm{ZrC}$ pristine surfaces. Distances between surface atoms.

\begin{tabular}{|c|c|c|c|c|}
\hline & $\mathrm{Pt}(111)$ & $\delta-\mathrm{MoC}(001)$ & $\operatorname{TiC}(001)$ & $\operatorname{ZrC}(001)$ \\
\hline $\mathrm{C}-\mathrm{C}(\AA)$ & -- & 3.08 & 3.06 & 3.32 \\
\hline $\mathrm{M}-\mathrm{M}(\AA)$ & 2.82 & 3.08 & 3.06 & 3.34 \\
\hline $\mathrm{C}-\mathrm{M}$ & -- & 2.19 & 2.17 & 2.36 \\
\hline
\end{tabular}

Table 2. Adsorption energies (eV) for $\pi-, \sigma$ - and $H$-down1 modes of ethylene over surfaces of Pt, $\delta$-MoC, $\mathrm{TiC}$ and $\mathrm{ZrC}$.

\begin{tabular}{|c|c|c|c|c|}
\hline Adsorption mode & $\operatorname{Pt}(111)$ & $\delta-\operatorname{MoC}(001)$ & $\mathrm{TiC}(001)$ & $\mathrm{ZrC}(001)$ \\
\hline$\pi-\mathrm{M}$ & -0.78 & -0.53 & -0.10 & -0.12 \\
\hline di- $\sigma-M M$ & -1.08 & 0.12 & 0.00 & 0.19 \\
\hline $\mathrm{H}-\mathrm{M}, \mathrm{H}-\mathrm{M}$ & 0.02 & -0.49 & 0.01 & 0.15 \\
\hline$\pi-C$ & -- & -0.10 & 0.15 & 0.12 \\
\hline di- $\sigma-C C$ & -- & 0.04 & -0.45 & 0.22 \\
\hline$\sigma-C$ & -- & -0.28 & 0.50 & 0.17 \\
\hline $\mathrm{H}-\mathrm{M}, \mathrm{H}-\mathrm{C}$ & -- & -0.50 & -0.01 & 0.18 \\
\hline $\mathrm{H}-\mathrm{C}, \mathrm{H}-\mathrm{C}$ & -- & -0.53 & -0.03 & 0.16 \\
\hline
\end{tabular}




\section{Figure Captions}

Figure 1. Ethylene adsorption over Pt(111) surface. a) di- $\sigma-M M$ mode. b) $\pi-M$ mode. Top: Top view, bottom: side view. Gray balls: Pt. Q: Mulliken charge of the adsorbed ethylene molecule.

Figure 2. Top: Surface sites of TMC(001) surface, top view. Bottom: Initial configurations of ethylene respect to the surface, side view. M (Mo, Ti, Zr): yellow, C: brown, H: light beige.

Figure 3. Ethylene adsorption modes on $\mathrm{TMC}(001)$ with some similarities to $\mathrm{Pt}(111)$. M (Mo, $\mathrm{Ti}, \mathrm{Zr}$ ): yellow, C: brown, H: light beige.

Figure 4. Charge isosurface $\left(0.05 \mathrm{e} / \AA^{3}\right)$ for pristine surfaces, top view. Blue and yellow represent regions where charge density was earned (C) and lost (metal), respectively, after the carbide formation. $\mathrm{Q}_{\mathrm{M}}$ : Mulliken charge for $\mathrm{M}$ atoms.

Figure 5. Most stable adsorption mode in every surface. Top and side view (bottom) a) $\mathrm{Pt}(111)$, b) $\delta$-MoC(001), c) $\mathrm{TiC}(001), \mathrm{d}) \mathrm{ZrC}(001)$. C-C: ethylene bond length. Pt: gray, Mo: Magenta, Ti: blue, Zr: green, C: brown, H: light beige.

Figure 6. $\pi$-bond-M adsorption of ethylene. Top: CCD, plotted from - 0.1 (blue) to 0.1 (red) e $/ \AA^{3}$. Bottom: Charge isosurface $0.05 \mathrm{e} / \AA^{3}$, blue and yellow represent the zones where charge was earned and lost, respectively.

Figure 7. Top: Side view before and after ethylene adsorption on $\delta$-MoC(001) via $\pi$-C. Bottom: CDD, plotted from -0.1 (blue) to 0.1 (red) e/ $\AA^{3}$. C-C: ethylene bond length.

Figure 8. a) Adsorption in di- $\sigma$-bond-CC mode, b) H-C, H-C adsorption mode. Top: top and side view of adsorbed ethylene. Bottom: CDD (left) and charge isosurface, $0.05 \mathrm{e} / \AA^{3}$ (right). CDD plotted from -0.1 (blue) to 0.1 (red) e/ $\AA^{3}$. C-C: ethylene bond length. 

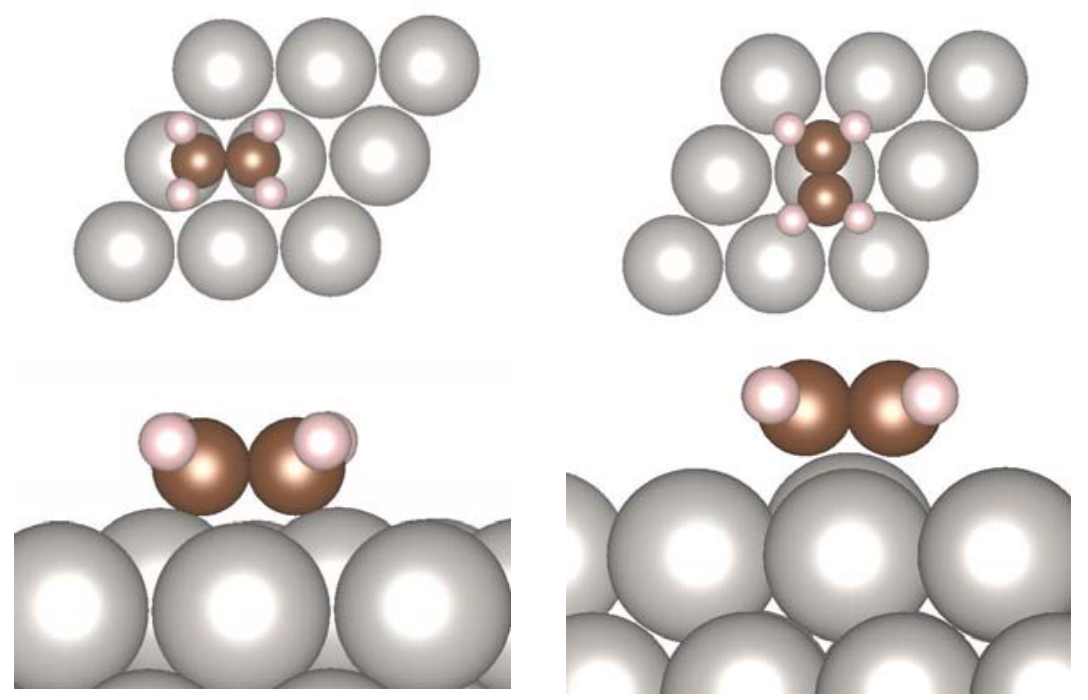

$$
\begin{gathered}
\mathrm{E}_{\mathrm{ads}}=-1.08 \mathrm{eV}(\mathrm{Q}=-0.56 \mathrm{e}) \\
\mathrm{C}-\mathrm{C}=1.48 \AA
\end{gathered}
$$

a)

$$
\begin{gathered}
\mathrm{E}_{\mathrm{ads}}=-0.78 \mathrm{eV}(\mathrm{Q}=-0.40 \mathrm{e}) \\
\mathrm{C}-\mathrm{C}=1.41 \AA
\end{gathered}
$$

b)

Figure 1. Ethylene adsorption over $\operatorname{Pt}(111)$ surface. a) di- $\sigma-\mathrm{MM}$ mode. b) $\pi$-M mode. Top: Top view, bottom: side view. Gray balls: Pt. Q: Mulliken charge of the adsorbed ethylene molecule.

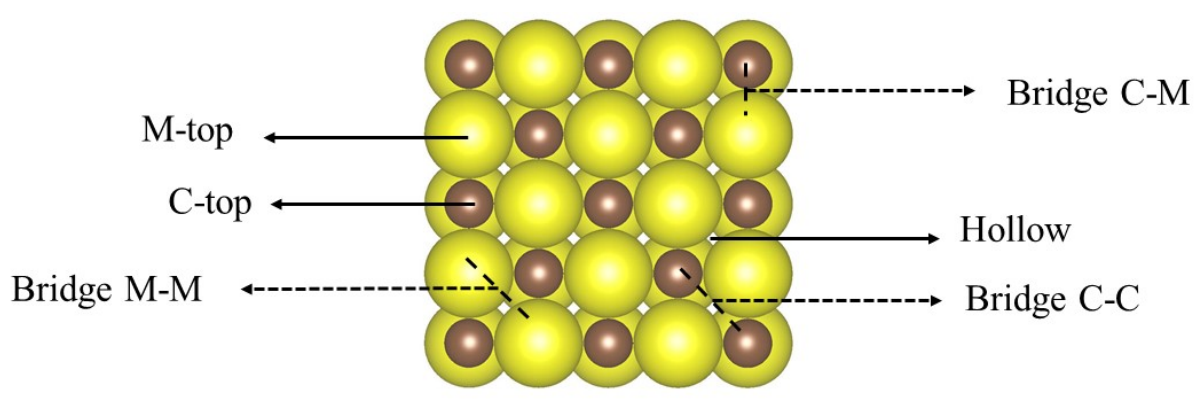

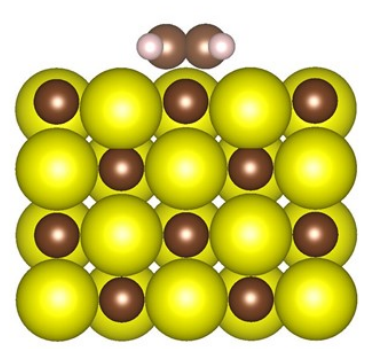

Configuration 1 (H-parallel)

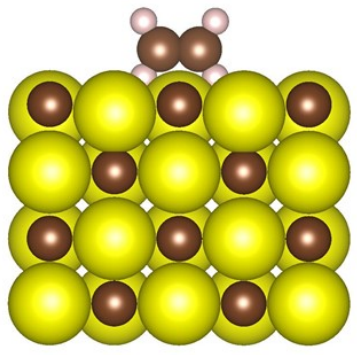

Configuration 2 (H-down 1$)$

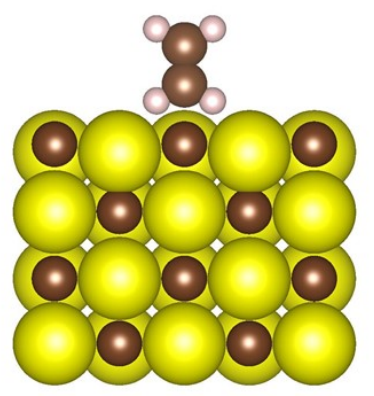

Configuration 3 (H-down2)

Figure 2. Top: Surface sites of TMC(001) surface, top view. Bottom: Initial configurations of ethylene respect to the surface, side view. M (Mo, Ti, Zr): yellow, C: brown, H: light beige. 


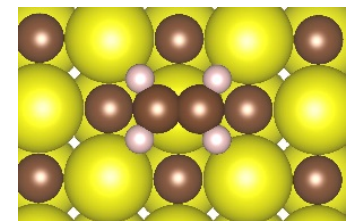

a) $\pi-\mathrm{M}$

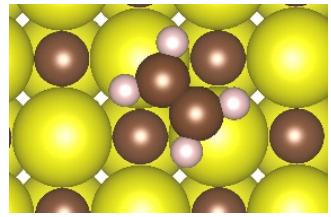

b) di- $\sigma-\mathrm{MM}$

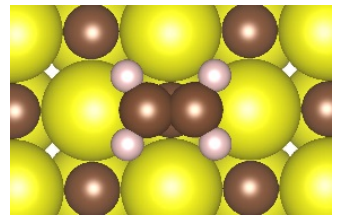

c) $\pi-\mathrm{C}$

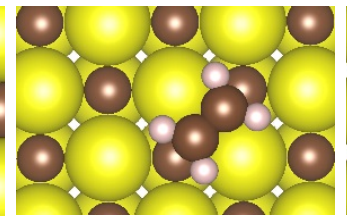

d) di- $\sigma-\mathrm{CC}$

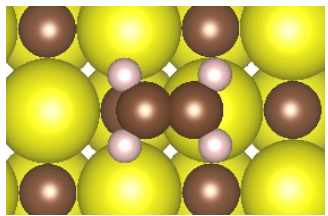

e) di- $\sigma-C M$

Figure 3. Ethylene adsorption modes on $\mathrm{TMC}(001)$ with some similarities to $\operatorname{Pt}(111)$. M (Mo, Ti, $\mathrm{Zr}$ ): yellow, C: brown, $\mathrm{H}$ : light beige.

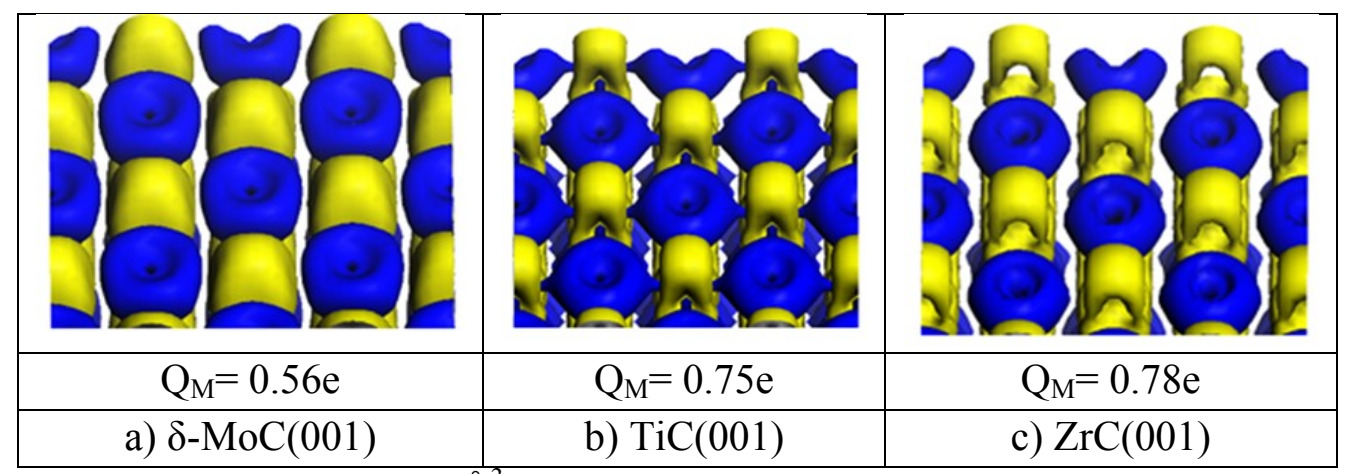

Figure 4. Charge isosurface $\left(0.05 \mathrm{e} / \AA^{3}\right)$ for pristine surfaces, top view. Blue and yellow represent regions where charge density was earned $(\mathrm{C})$ and lost (metal), respectively, after the carbide formation. $\mathrm{Q}_{\mathrm{M}}$ : Mulliken charge for $\mathrm{M}$ atoms. 

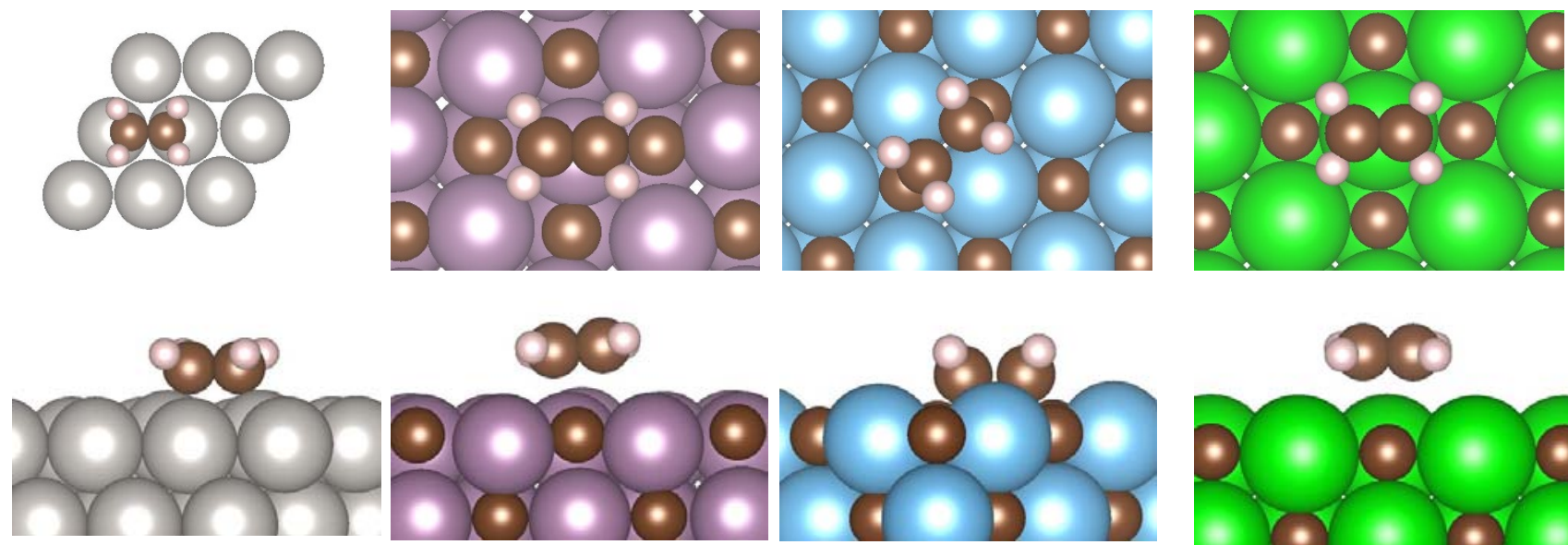

$\mathrm{E}_{\mathrm{ads}}=-1.08 \mathrm{eV}$

$E_{a d s}=-0.53 \mathrm{eV}$

$E_{a d s}=-0.45 \mathrm{eV}$

$\mathrm{C}-\mathrm{C}=1.36 \AA$

$\mathrm{C}-\mathrm{C}=1.64 \AA$

b)

c)

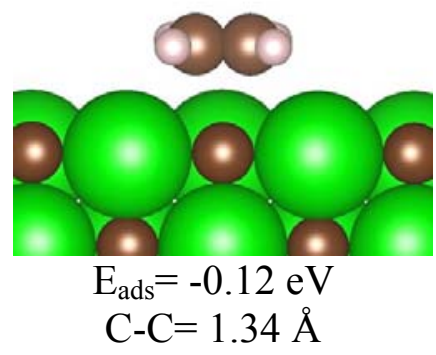

a)

d)

Figure 5. Most stable adsorption mode in every surface. Top and side view (bottom) a) $\operatorname{Pt}(111)$, b) $\delta$-MoC(001), c) $\operatorname{TiC}(001)$, d) $\operatorname{ZrC}(001)$. C-C: ethylene bond length. Pt: gray, Mo: Magenta,

Ti: blue, Zr: green, C: brown, $\mathrm{H}$ : light beige.

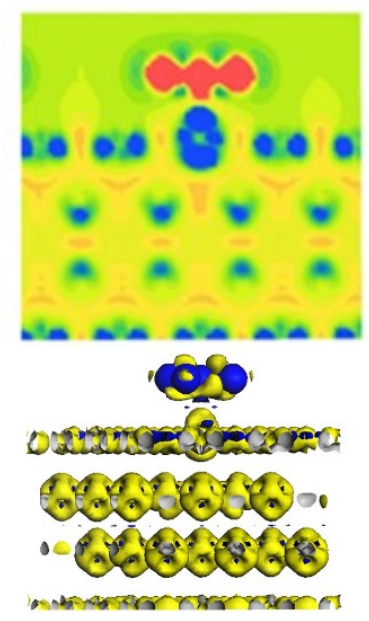

$E_{\text {ads }}=-0.78 \mathrm{eV}$

$\operatorname{Pt}(111)$
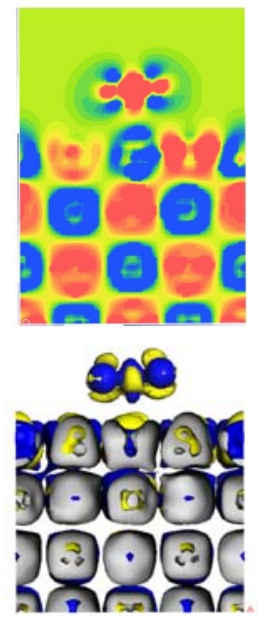

$\mathrm{E}_{\mathrm{ads}}=-0.53 \mathrm{eV}$

$\delta$-MoC $(001)$
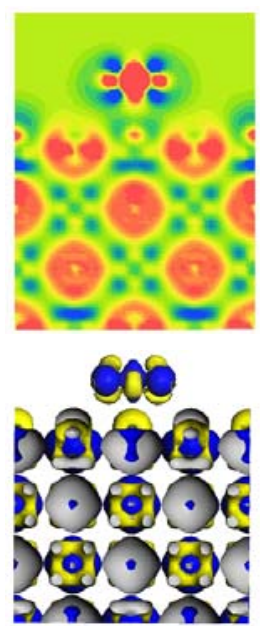

$\mathrm{E}_{\mathrm{ads}}=-0.12 \mathrm{eV}$

$\mathrm{ZrC}(001)$

Figure 6. $\pi$-bond-M adsorption of ethylene. Top: CCD, plotted from -0.1 (blue) to 0.1 (red) e/ $/ \AA^{3}$. Bottom: Charge isosurface $0.05 \mathrm{e} / \AA^{3}$, blue and yellow represent the zones where charge was earned and lost, respectively. 

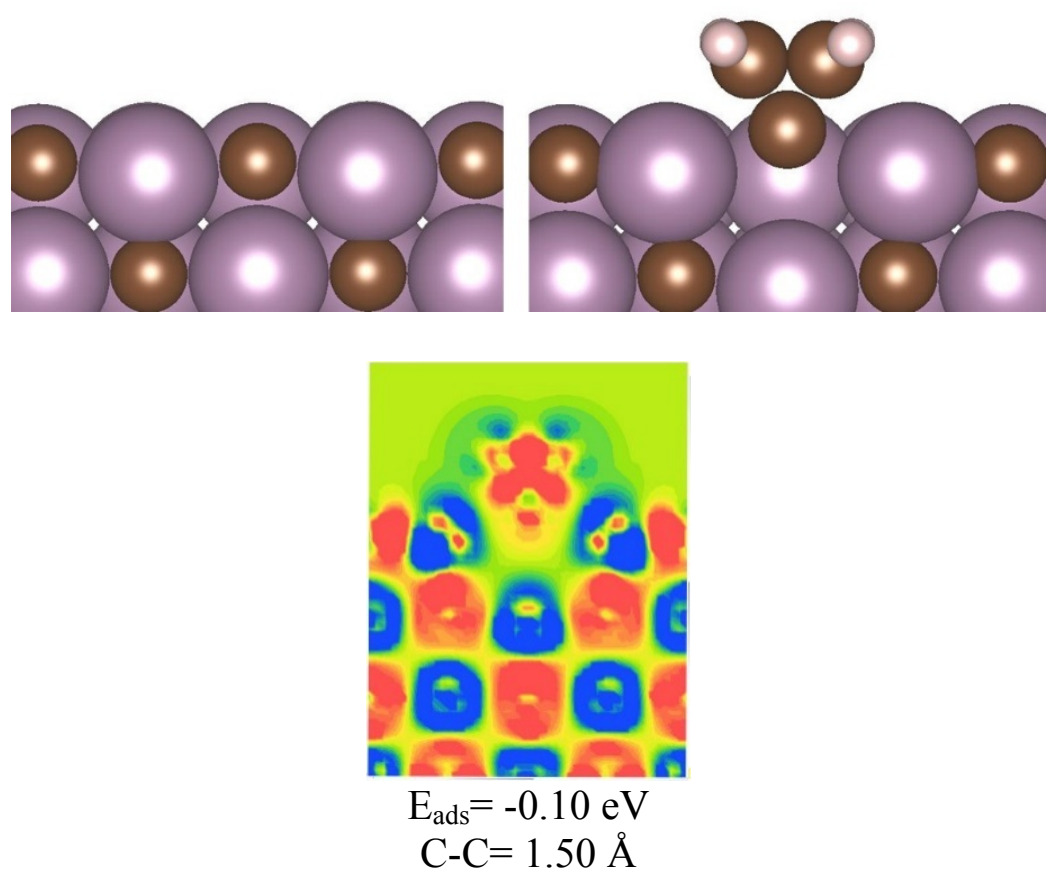

Figure 7. Top: Side view before and after ethylene adsorption on $\delta$-MoC(001) via $\pi$-C. Bottom: $\mathrm{CDD}$, plotted from -0.1 (blue) to 0.1 (red) $\mathrm{e} / \mathrm{A}^{3}$. C-C: ethylene bond length. 

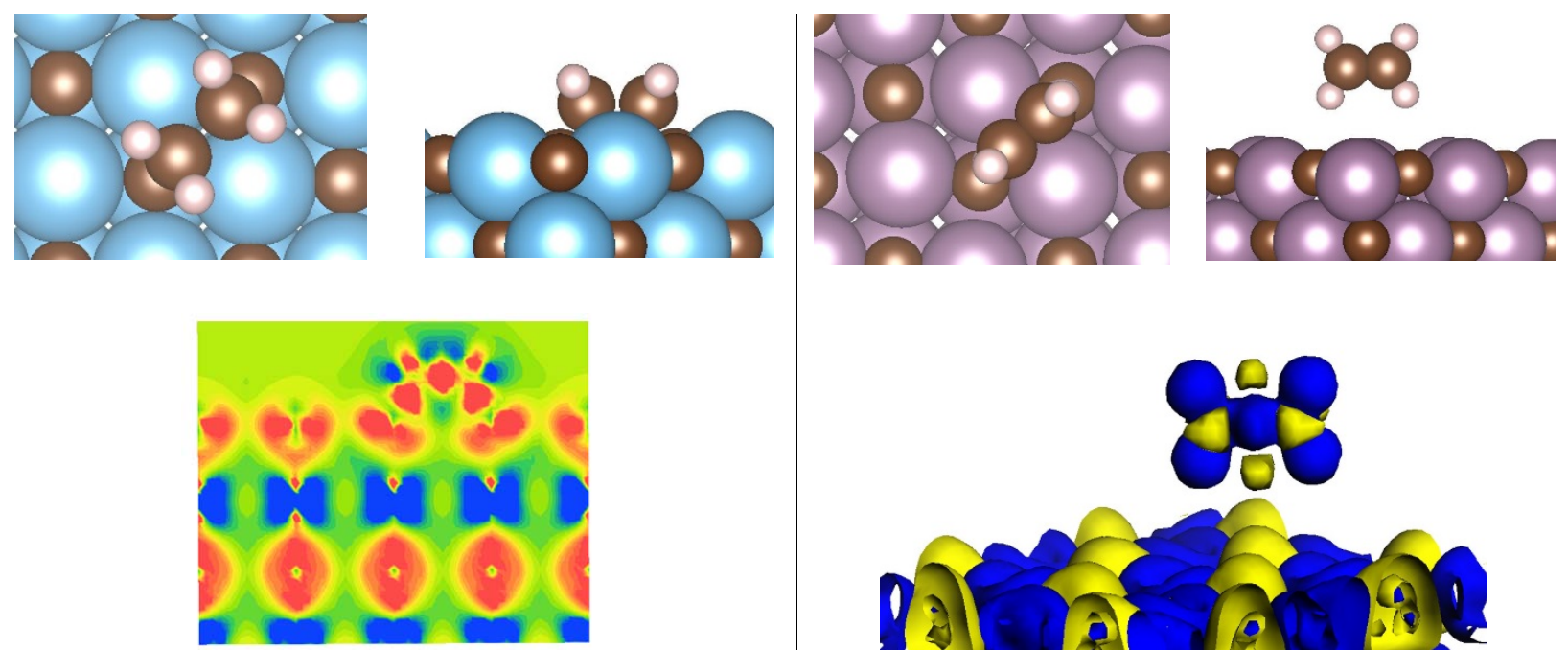

$\mathrm{E}_{\mathrm{ads}}=-0.45 \mathrm{eV}, \mathrm{C}-\mathrm{C}=1.64 \AA$

a) $\mathrm{TiC}(001)$

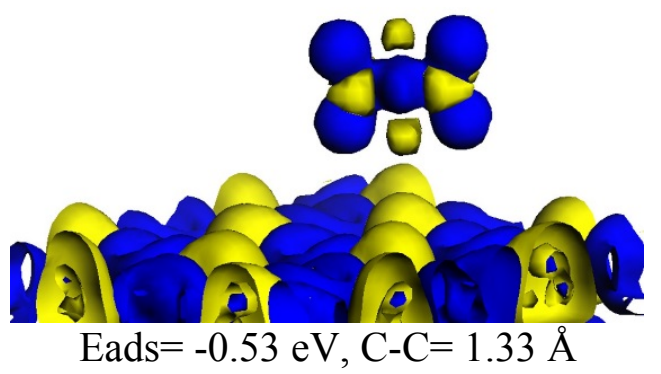

b) $\delta-\mathrm{MoC}$

Figure 8. a) Adsorption in di- $\sigma$-bond-CC mode, b) H-C, H-C adsorption mode. Top: top and side view of adsorbed ethylene. Bottom: CDD (left) and charge isosurface, $0.05 \mathrm{e} / \AA^{3}$ (right). CDD plotted from -0.1 (blue) to 0.1 (red) $\mathrm{e} / \AA^{3}$. C-C: ethylene bond length. 


\section{TOC}

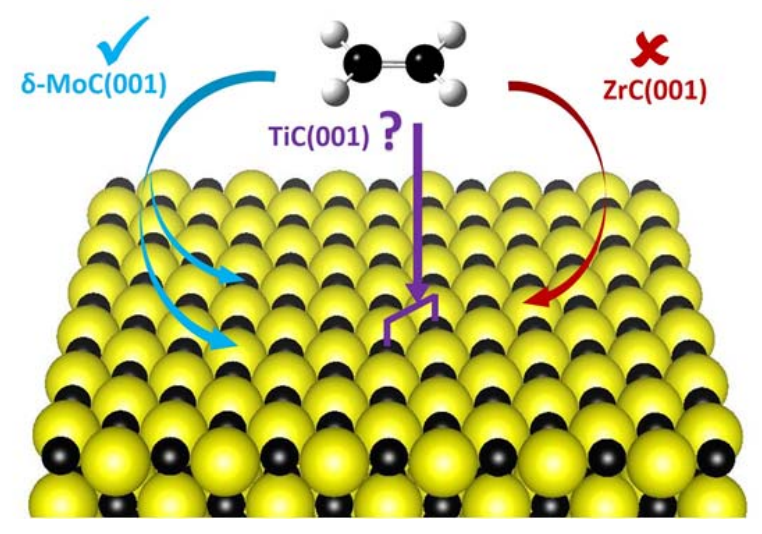

